\title{
二维材料器件青年学者一一浙江大学徐杨教授访谈
}

《物理化学学报》编辑部

北京大学化学与分子工程学院, 北京 100871

\section{A Short Dialogue about 2D Material Based Devices with Prof. Yang Xu at Zhejiang University}

\author{
Editorial Office of Acta Physico-Chimica Sinica \\ College of Chemistry and Molecular Engineering, Peking University, Beijing 100871, P. R. China. \\ Email:whxb@pku.edu.cn.
}

Published online: May 30, 2019.

本期人物访谈, 我们对话的是二维材料及器件特刊客座编辑、浙江大学徐杨教授。

在访谈中, 徐老师给我们介绍了二维材料的发展历程、独特性质、潜在应用、发展趋势。并且给有志 于从事二维材料研究的青年学生提出了非常中肯的建议, 希望能对大家有所启示。

问题 1: 二维材料有无明确的科学定义?

回答: 关于二维材料, 没有绝对明确的科学定义, 但科学界普遍认同的概念是指电子仅可在两个维 度, 大概一到几十纳米平面内可自由运动的材料。

在石墨烯发现之前, 二维纳米结构主要是III$\mathrm{V}$ 族的量子阱。通过分子束外延(MBE)技术选择晶 格匹配的两种化合物半导体材料, 控制外延层的 厚度在纳米量级获得二维电子势阱。

近年来提出的二维材料的概念, 是从2004年 曼切斯特大学 Geim小组成功分离出单原子层 0.34 $\mathrm{nm}$ 的石墨烯而出现的。大多数科学家对二维材料 的厚度并没有严格的规定, 主要还是以和三维体 材料在性能上的不同加以区分。

\section{问题 2: 二维材料是如何被发现的?}

回答: 最开始理论物理认为单层石墨(石墨烯)是不 可能在现实中独立存在的。于是 2004 曼切斯特大 学Geim小组想将石墨磨至只剩10-100层厚, 然后 研究它的性质。但当时只磨出大约 1000 层厚的石 墨细片, 距离目标差一点。于是他们利用透明胶带 将它的上层剥下, 薄片便会剥黏在胶带上。重复数 次相同的过程, 胶带上就黏着越来越薄的石墨薄
片。2004年10月，Geim在Science杂志发表了一篇 题为Electric Field Effect in Atomically Thin Carbon Films的论文, 宣布制备出石墨烯片, 之后二维材 料被广泛关注, 持续至今。

问题 3: 科学家为何对二维材料产生了浓厚的兴 趣?

回答: 二维材料因其特殊的物理特性而引起广泛 的关注, 不同应用中的关键特性都被很大程度地 提升。二维材料独特的光电特性或许会在高效, 宽 带、柔性、透明、低功耗等方面的新一代的器件发 挥独特作用, 因此促使了大量相关的研究。

此外从绝缘体氮化硼, 半导体过渡金属硫化 物, 到金属特性的石墨烯, 它们各种堆叠和排列的 组合, 展示了二维材料特性的多样性, 或许会带来 科学上的重要发现。

问题 4: 二维材料发展历程中, 有哪些里程碑式的 发现?

回答: 里程碑式的物理发现, 以石墨烯为例主要体 现在: (1)在发现石墨烯以前, 大多数物理学家认 为, 热力学涨落不允许任何二维晶体在有限温度 
下存在, 但是单层石墨烯能够在实验中被制备出 来, 所以它的发现立即震撼了凝聚体物理学学术 界。(2)石墨烯中电子和空穴载流子的半整数量子 霍尔效应在室温下就通过电场作用改变化学势观 察到。(3)石墨烯中的载流子在碰到杂质时一般不 会产生背散射, 石墨烯具有局域超强导电性以及 很高的载流子迁移率。

问题5: 您预计未来会发现哪些新的二维材料?

回答: Drexel大学的Yury Gogotsi教授说过: “一 个 50 岁的科学家在实验室玩新玩具和一个 5 岁小 孩在家里玩新玩具的乐趣没什么不一样, 二维材 料就是我的新玩具!”在石墨烯之外, 目前在二维 材料发展了几大体系, 比如: TMDs、MXenes、2D Organic materials、BP、硅烯、锗烯、Nitrides和二 维钻铁矿等等。未来还有可能制备出更多新的二 维材料。

问题6: 二维材料有哪些应用实例? 在哪些领域有 开拓性的应用?

回答: 二维材料是当下的前沿领域之一, 涵盖了印 刷电子、柔性电子、超级电容、太阳能电池、量子 点、传感器、光电探测器、半导体制造等, 具有优 异的机械、热学、光学特性, 是这些领域实现颠覆 式创新的基础。

问题 7: 目前二维材料发展的最大的挑战有哪些?

回答: 虽然二维材料的性质探索、制备表征和器件 应用都已有较好的发展, 但距离其产业化应用还较 远。在大面积高质量材料及其特定复合结构的可控 制备、低能耗高集成度器件的结构设计、大规模材 料器件印刷技术, 与传统材料产业链的结合等方面 还有巨大的挑战。此外, 二维材料家族中仍有不少 材料尚未被制得, 其物理、化学性质有待揭示。
问题8: 二维材料发展和应用对普通人的生活会有 哪些影响?

回答: 如今, 二维材料研究在诸如: 自旋电子、印 刷电子、柔性电子、微电子、存储器、处理器、超 透镜、太赫兹、超级电容、太阳能电池、防伪标签、 量子点、传感器、探测器、半导体制造、NFC、医 疗等领域开展了广泛的基础研究。但目前市场上, 还没有看到大规模相关的日常生活产品。二维材 料与器件的应用还有很多挑战和困难, 希望能在 不久的将来 “飞入平常百姓家”。

问题9: 您对准备从事二维材料研究的年轻学生有 何建议?

回答: Geim在发现石墨烯获得诺贝尔奖之前, 于 1997年使用磁场让一只青蛙漂浮升空, 登上报纸 头版头条, 于 2000 年获得搞笑诺贝尔奖。他曾和他 的仓鼠宠物共同发表一篇论文《探测地球自转的 反磁性悬浮回转仪》。2007年, 他的实验室开发出 一种仿照壁虎黏性脚垫的微制造黏着剂。Geim擅 长寻找古怪但有重要性的研究题目, 所以未来准 备从事二维材料研究的年轻学生应该学习Geim的 这种打破常规的思维方式, 敢于探索关键科学问 题的精神。

问题 10：您可否预测一下二维材料未来的发展趋 势?

回答: 未来二维材料可在调控催化和电学性能、光 电器件性能的提升、可穿戴智能器件、柔性电子、 储能器件等方面有更多的提升空间。对二维材料 的工艺流程, 诸如互连接触、掺杂、栅极加工、图 形化及其刻蚀、系统集成等方面的问题都需要解 决。这些将实验室的概念器件推向大规模生产制 造, 还有很多重大困难需要突破, 才有可能使得二 维材料进入产业化发展。

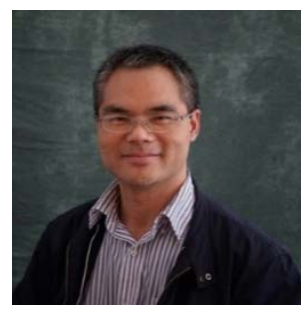

徐杨, 浙江大学微电子学院教授, Professor of ZJU-UIUC Joint Institute, 英国剑桥 大学丘吉尔学院学者, UCLA访问教授。清华大学电子工程系微电子学与固体电子学学 士; 美国伊利偌伊大学厄巴纳-香槟分校电子工程系博士。徐杨教授长期从事硅基非可 见光探测器的设计与制备, 专注于与新材料集成的硅基图像传感器系统研究。在Nat. Commun、Adv. Mater、Nano Lett. 等期刊和IEDM会议上发表论文60余篇, 发明专利授 权10余项。曾承担国家自然科学基金 5 项，参与国家重点研发 1 项。 